\title{
The Agricultural Heritage Value of the Polder System in Gaochun, Nanjing
}

\author{
Bohan Tang, Xuqiang Zhan and Jie Zhang* \\ Institute of Architecture and Urban Studies, Tsinghua University, Beijing, China \\ * Corresponding author: zjzhangjie@tsinghua.edu.cn
}

\begin{abstract}
Polder is a unique form of reclaimed farmland steeped in human history of long-term adaptation to nature. It embodies traditional agricultural technologies, water conservancy technologies and the culture of the agricultural society, providing great value in terms of agricultural heritage. The polder system in Gaochun, Nanjing was born out of the exploitation and use of the lakeside intertidal zone and is a typical example of Jianghuai polders in the Yangtze River delta region. However, because of neglect of its heritage value, the Gaochun polder system is facing the impact of farmland modernisation, and it is urgent to affirm its value and implement dynamic protection. This research explores the historical development and spatial features of the Gaochun polder system, and evaluates its heritage value within the framework of GIAHS (Globally Important Agricultural Heritage Systems) from aspects of (1) food and livelihood security; (2) agro-biodiversity; (3) local and traditional knowledge systems; 4) cultures, value systems and social organisations; and 5) landscapes features. Based on our recognition of the agricultural heritage value of the Gaochun polder system, we put forward suggestions for its dynamic conservation and adaptive management while maintaining its productive functions.
\end{abstract}

KEYWORDS polder, Gaochun, farmland water conservancy, agricultural heritage, GIAHS

Received November 2, 2018; accepted February 3, 2019.

\section{Introduction: Polder as a Form of Built Heritage}

Although it originated in the Netherlands and is mainly used to refer to the flat and open landscapes of northwestern Europe (Meeus 1995), the term 'polder' can refer to a form of agricultural landscape with profound traditions in various regions over the world where waterlogging or inundation occurs permanently including fens and bogs, shallow sea and lake beds, or temporarily, including tidal lowlands and river plains (Nijhuis 2016). Segeren (1983) defined a polder as 'a level area which was originally subject to a high water-level, either permanently or seasonally and due to either groundwater or surface water. It becomes a polder when it is separated from the surrounding hydrological regime so that its water-level can be controlled independently of the surrounding regime. Based on this definition, polder landscapes can be categorised into three typologies: impoldered low-lying lands, lands reclaimed from the sea, and drained lakes (Nijhuis 2016).
International scholars (mainly Dutch) have intensively studied polders from the perspectives of land and water management, construction technology, agriculture and food production, physical planning and landscape and socio-economic aspects (ILRI 1982; Guo and Hou 2015). By integrating those perspectives, the heritage value of polders has been actively explored and conserved, including successfully recognising Droogmakerij de Beemster (Beemster Polder) as a UNESCO World Heritage site (UNESCO 1999).

While there are few published case studies on polders in China, impolderment or land reclamation has been a common water conservancy practice in different parts of China for a long time (Figure 1). The closest Chinese counterpart term of polder is wei or weitian, which refers to diked fields in low wetlands and also has regional variations such as hutian or yuantian (Ning 1958). Originating in the $\mathrm{BC}$ era and maturing around $1000 \mathrm{AD}$, polders in China are mainly clustered in two major regions: the middle reaches of the Yangtze River including present-day 


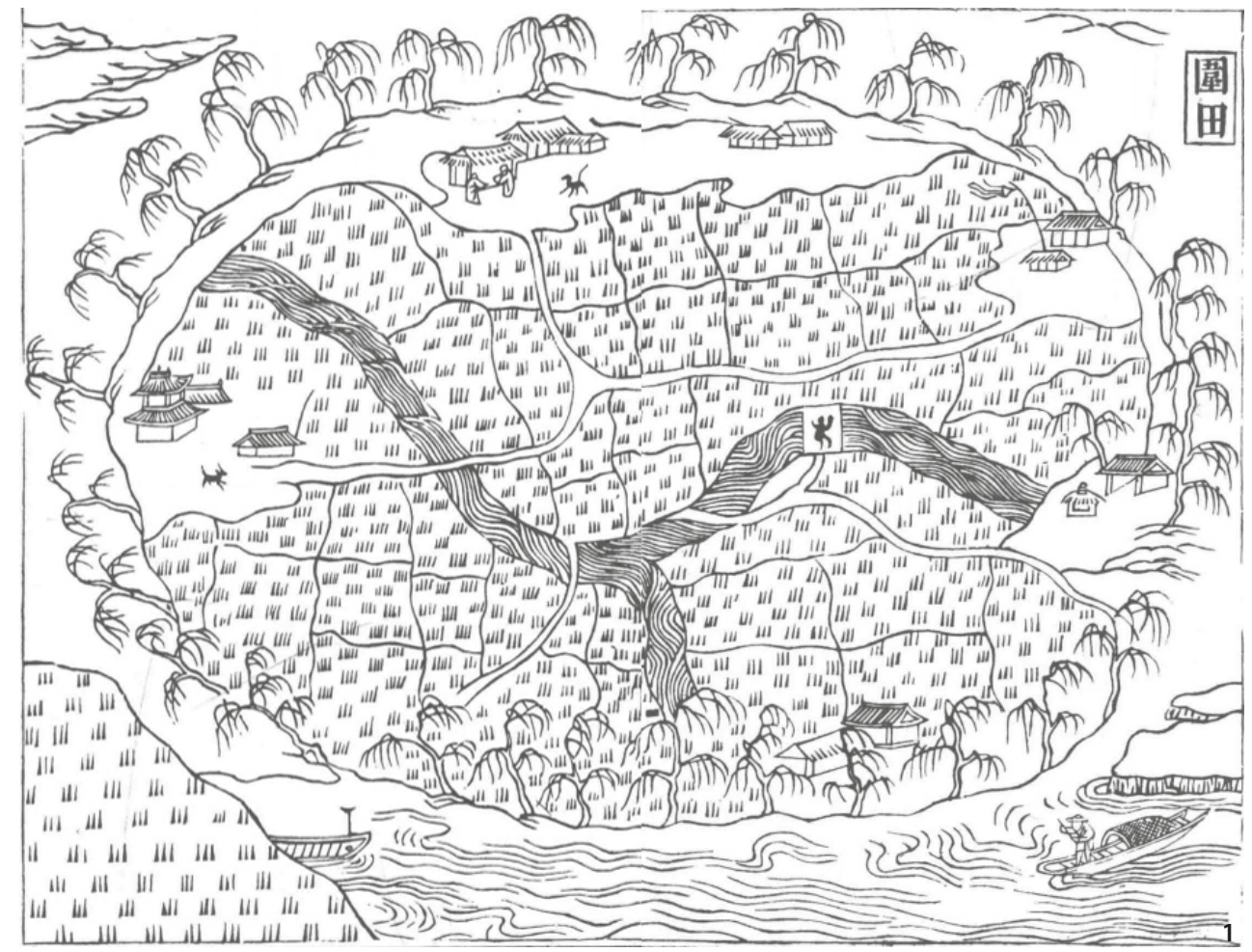

Figure 1 Ancient polder diagram drawn in 1271-1368 (Source: Wang 2015).

Hunan, Hubei and Jiangxi provinces, and in the Yangtze River delta including Anhui, Jiangsu, Zhejiang provinces and the city of Shanghai (Ji 1964).

Although there have been numerous historical overviews and case studies on polders in Chinese literature from geographical, agricultural, ecological, landscape, engineering, social and economic disciplines (Zhao and Liu 2003; Guo and Hou 2016), few Chinese scholars have inspected polder as a built heritage and systematically evaluated its heritage value.

\section{Methodology: Agricultural Heritage Evaluation within the Framework of GIAHS}

Among the agroecosystems of different age, structure and management, agricultural heritage systems are those that have proven to be sustainable in their historical and ecological context (Altieri and Koohafkan 2004). However, many of these systems are facing severe threats from various sources including urbanisation, industrialisation and globalisation, especially in developing countries. In recent years, countries and organisations around the world have paid ever more attention to the identification and protection of the value of agricultural heritage. In 2002, the Food and Agriculture Organisation of the United Nations (FAO) initiated the GIAHS (Globally Important Agricultural
Heritage Systems) project to promote the international identification, dynamic protection and sustainable management of agricultural heritage systems.

FAO (2002) defines GIAHS as 'Remarkable land use systems and landscapes which are rich in globally significant biological diversity evolving from the co-adaptation of a community with its environment and its needs and aspirations for sustainable development', and the identification standard of the GIAHS includes five aspects: (1) food and livelihood security; (2) agro-biodiversity; (3) local and traditional knowledge systems; (4) cultures, value systems and social organisations; (5) landscapes and seascapes features.

As a comprehensive, dynamic and strategic model of the agricultural heritage concept, the GIAHS framework emphasises the integration of an ecological domain, a human domain, and a historical domain as a system. Min et al. (2011) point out that while GIAHS shares the concept of cultural landscape to a certain extent, the GIAHS framework is more focused on biodiversity conservation and representation of intangible systems.

GIAHS is becoming globally recognised as an evaluation framework as well as a conservation practice agenda. Since 2005, the FAO has carried out theoretical research and practical exploration on GIAHS protection with the first batch of pilot countries including China. Studies on China's agricultural heritage date back to the end of the $19^{\text {th }}$ century, but studies prior to the $21^{\text {st }}$ century are 


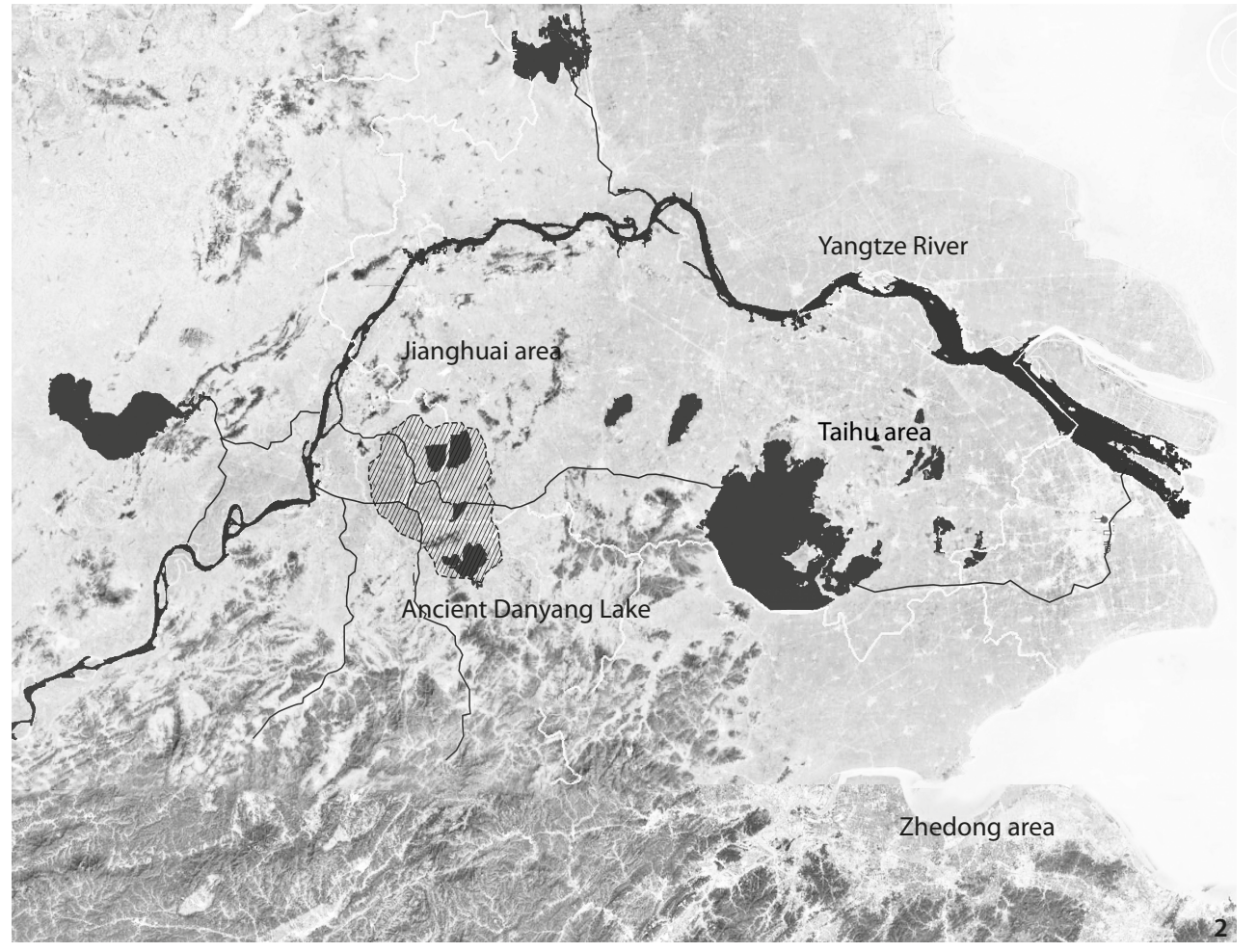

Figure 2 Distribution map of different types of polder (Source: the author). mainly document-based and have focused on historical perspectives such as agricultural archaeology, agricultural species and technology, and intangible heritage such as traditional agricultural theory and agricultural folklore among others (Wang and Lu 2010). Since the introduction of the GIAHS concept in China, research interests have taken a practice-oriented shift, focusing on comprehensive heritage evaluation and dynamic conservation of China's agricultural heritage resources.

According to the FAO website, as of 2018, 57 projects in 22 countries around the world have been initiated. 15 of these 57 GIAHS projects are in China, which has the largest number of projects of any country, including the Qingtian Rice-Fish Culture System (RFC), the Hani Rice Terraces System and the Xinghua Duotian Agrosystem.

\section{General Features of the Gaochun Polder System}

The Gaochun District used to be on the shore of the Ancient Danyang Lake, and is now located in the southwest of Jiangsu Province, south of Nanjing (Xue 1988). Later the Ancient Danyang Lake (which transformed over time into Gucheng Lake, Shijiu Lake and now Danyang Lake) was divided into three lakes and multiple intertidal zones because of sediment accumulation (He 2016). According to the official statistics of the Gaochun County Yearbook
(Gaochun County Office 2011), the Gaochun District covered a total area of $802 \mathrm{~km}^{2}$, in which hills accounted for $57 \%$ and polder areas were $43 \%$. Surrounded by the three main lakes, the low-lying areas in the west of Gaochun District gradually became contiguous polders with an elevation from 5 to $7 \mathrm{~m}$.

Based on location, He (2003) categorised polders in the Yangtze River delta region into three groups: JiangHuai (Yangtze and Huaihe rivers) area, Taihu (Taihu Lake) area and Zhedong (east Zhejiang) area, which differ in geographic environment and morphology (Figure 2). As a typical polder in the Jiang-Huai area, Gaochun polders are larger in scale and more separated in structure compared with polders in the Taihu area, and are cultivated at lower altitudes than those in the Zhedong area.

\section{Historical Development of the Gaochun Polder System}

According to historical records (Xue 1988), in the late Spring and Autumn Period, Wu State built Xiangguo Polder (770 BC-476 BC) in the Gucheng Lake area to provide grains for the army near the border; this became the earliest polder at that time, which was called 'the Peerless Polder'. In the late Northern Song Dynasty (11271279), the capital city was moved to Lin'an, Zhejiang in the Yangtze River Delta. The southward migration of a large number of people caused a dramatic increase in 

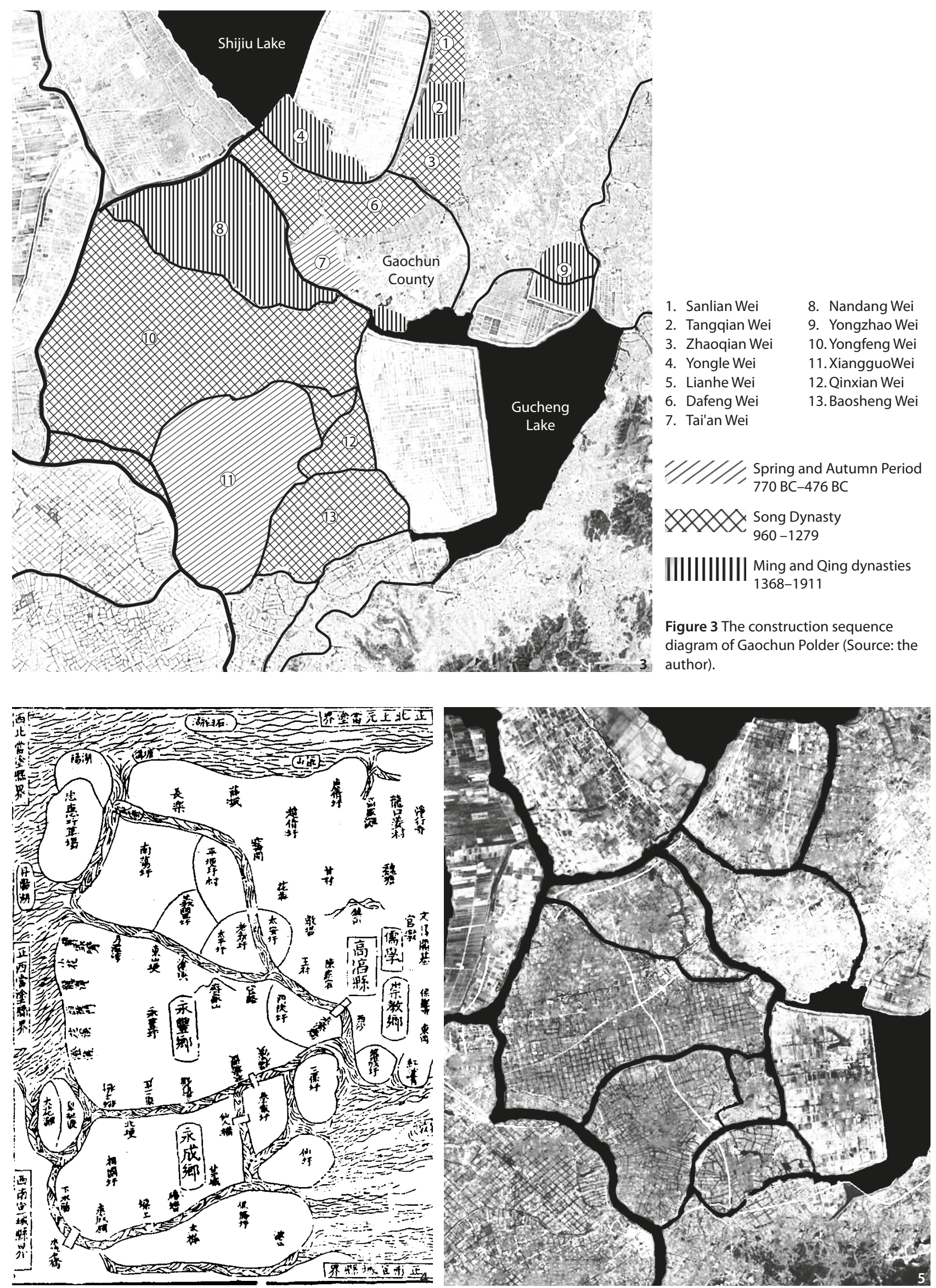

Figure 4 Water system map in Gaochun County Annals (Source: Xue 1988).

Figure $\mathbf{5}$ The current water system map of Gaochun (Source: the author). 

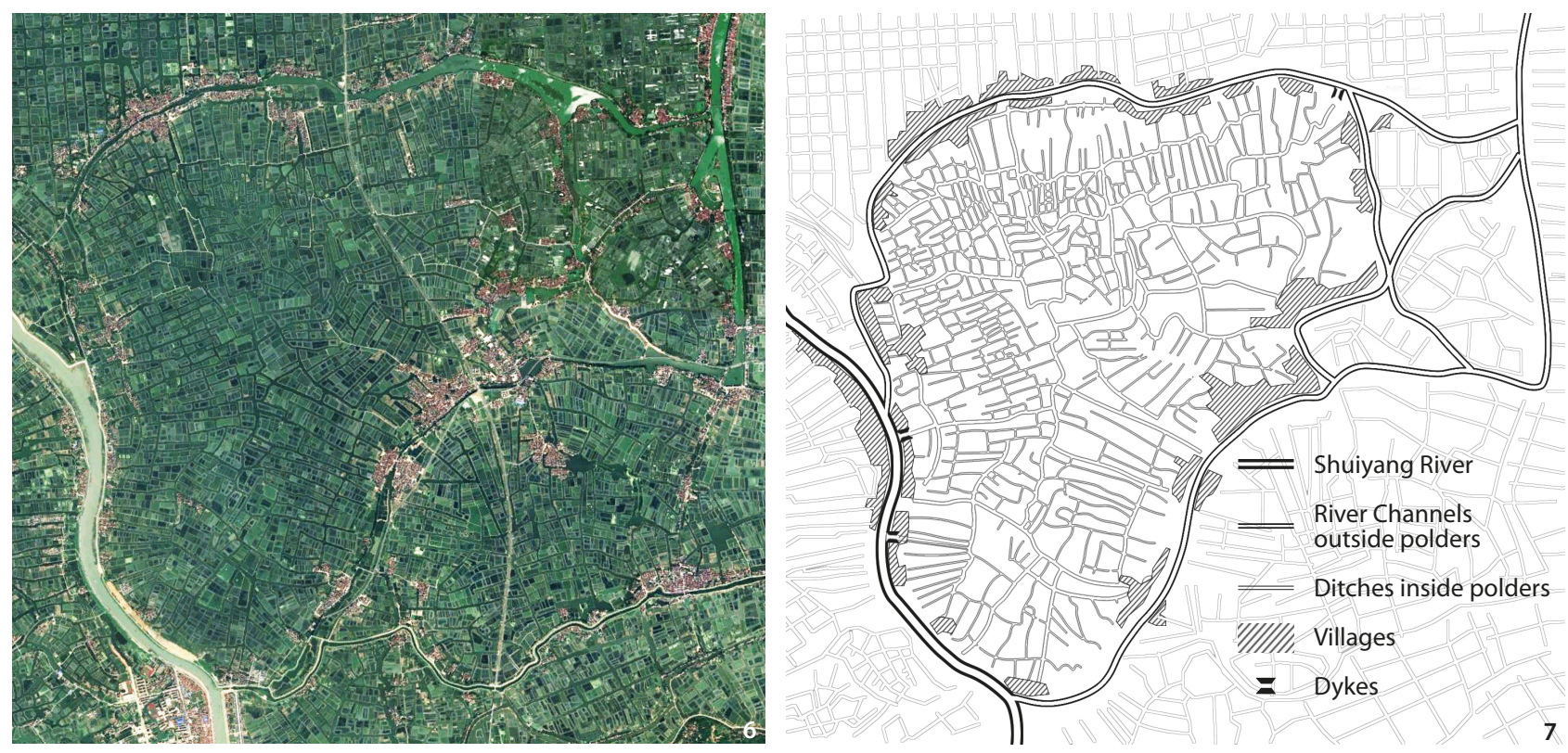

Figure 6 The satellite image map of Xiangguo Wei (Source: the author).

Figure 7 The water network classification diagram of Xiangguo Wei (Source: the author).

the population of the South. As the competition between people and land intensified, the polder thus became an important way to expand the agricultural production. The development of the polder fields in the south of the Yangtze River then entered a prosperous stage, and laid the development scale of the polder fields in this area (Zhuang 2005). During the Song Dynasty (960-1279), the large but independent form of the Xiangguo Polder was extended, and the vast polder fields such as Yongfeng Polder and Baosheng Polder were built in Gaochun. After the founding of the Ming Dynasty (1368-1644), in response to Zhu Yuanzhang's encouragement and reward for farming, people in Gaochun vigorously reclaimed polders from lakes, and built Nandang Polder, Yongle Polder and other new polder fields. With the dredging of the Xuxi River and the construction of Guangtongzhen Dam, Gaochun had become a granary, and local economic performance was strong (Zhao and Liu 2003). During the period of the Republic of China (1912-1949) and People's Republic of China in the $20^{\text {th }}$ century, a number of new polder fields, such as Yongsheng Polder and Yonglian Polder, were built for the development of agriculture and the expansion of reclamation (Figure 3).

\section{Spatial and Morphological Features of Polder Fields}

It is recorded in the Monograph of Water Conservancy in Wu Areas (Fan 1999), which was completed in the Northern Song Dynasty, that 'there should be a canal running north and south within a distance of five to seven $l i$ ( 1 li equals approximately to $0.4 \mathrm{~km}$ ), while a dike lying from the east to the west is dredged in seven to ten li (Figure 4). This indicates the existence of the institutional standard on the construction of the ancient canals, dikes and polder fields, which has been the product of people's adaptation to nature for a long time. Among these polders, Xiangguo Wei in Gaochun is about $4 \mathrm{~km}$ wide and $6 \mathrm{~km}$ long, and is similar to the recorded construction size, which embodies the techniques for the construction of government-owned farmlands in ancient times. The polder fields in Gaochun are relatively large, and the area of farmlands is about tens of $\mathrm{km}^{2}$. Shuiyang River passes through the western part of the polder area, and the northern part is the Shijiu Lake and the south is the Gucheng Lake. The western polder area is the lacustrine plain shaped by Gucheng Lake, Shijiu Lake and Danyang Lake. The terrain is low and flat with rivers and canals crisscrossed. There are many polder fields between the lakes, which are linked to each other by rivers (Figure 5).

In terms of morphology, the Gaochun polders enclose irregular ellipses, and the inner river network extends vertically from the boundary to inside, reflecting the adaptability of the polder to the natural environment. Based on the geomorphology of the water system and the proportions of single fields determined by remote sensing, the polder fields can be categorised into three types, namely crisscross pattern, feather shape and straight strip (Lu et al. 2006). Among the current polder fields in Gaochun (Figure 6), the form with a relatively long history is 


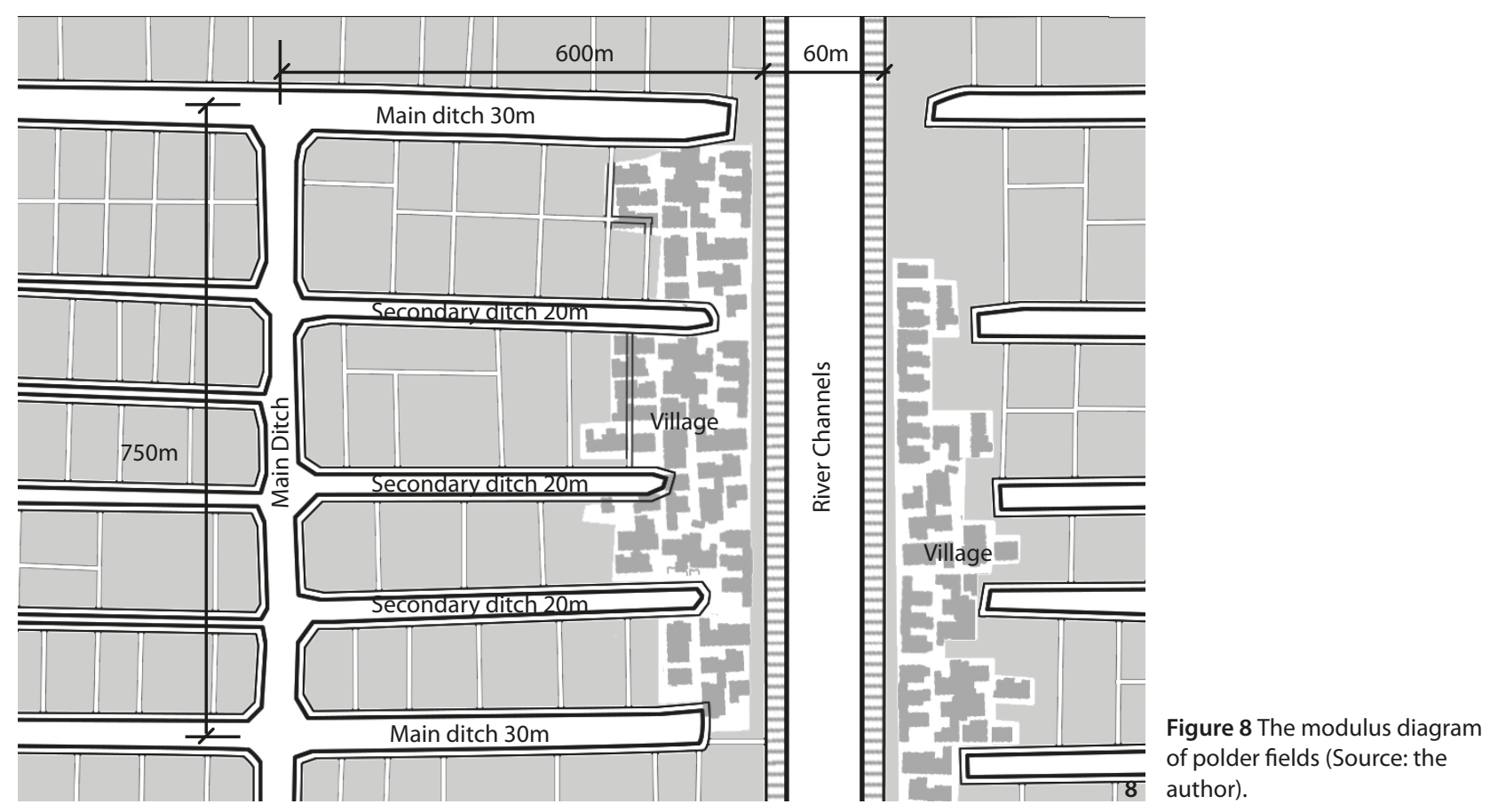

dominated by those in feather shape, and the modern polders are mainly in square grids. As the earliest local polder field built in the Spring and Autumn Period, Xiangguo Wei reflects the feather shape features of the primitive polder well. Among them, the width of a single field is about 80 to $100 \mathrm{~m}$, the major river is about 50 to $70 \mathrm{~m}$, and the secondary channels of the fields are about 20 to 30 $\mathrm{m}$. Through the river classification (Figure 7), single farmland units with an area about $750 \mathrm{~m} \times 600 \mathrm{~m}$ are formed. Meanwhile, the villages are distributed linearly on the river dikes near the field, which shows that there is a definite structure of building the polder for improved cultivation conditions (Figure 8).

\section{The Agricultural Heritage Value of Gaochun Polders}

Based on the criteria of GIAHS, the value of the Gaochun polder system in terms of agricultural heritage has been systematically and comprehensively analysed. Based on the types and environment of agricultural production, the GIAHS heritage is divided into types including the mountain terrace agricultural system, the compound planting system, the irrigation and water management system, the subsea system, the integrated farming and breeding system, and so forth. The polder highlights the features of both the irrigation and water management system and the compound planting system, which means it is a relatively comprehensive farmland water conservancy system.
Following the identification standard of GIAHS, Gaochun polders have highlighted the traditional knowledge system and applied technology of agriculture and water conservancy, coping with the grain and livelihood problems induced by population and forming a distinctive social organisation structure. The details are described in the following sections.

\section{High Grain Productivity and Supplies for Livelihood}

The main reason for the large-scale reclamation of polder fields in Gaochun is the conflict between humans and land brought about by population migration. Gaochun was located in the land of the so-called southern barbarians, within the ancient Wu State. Before the Qin (221 BC-207 BC) and Han (202 BC-220 AD) Dynasties, the population there was relatively small, and no shortage of farmlands existed. However, because of the three wars in Western Jin Dynasty (266 AD-316 AD) and Song Dynasty, the southward migration of nearly 10 million people led to a sharp increase in population density in the region south of the Yangtze River. According to statistics in China Annals of Yuanfeng (Wang, 1984), the population densities of Liangzhe $\mathrm{Lu}$ and Jiangdong $\mathrm{Lu}$ in Northern Song Dynasty ranked second and fourth of all the lu regions in the whole country. The original farmlands could not serve the increasing population, people thus gradually began to carry out large-scale enclosure and reclamation on the intertidal zones unfit for cultivation, launching a field building campaign, to handle the competition between people 
and land. According to incomplete statistics, the government-owned polder in Jiangdong Lu in the Song Dynasty covered more than 790 thousand $m u$ ( $1 \mathrm{mu}$ is equal to approximately $580 \mathrm{~m}^{2}$ in Song Dynasty), resulting in the development situation of 'connecting to Jiande near the central government while extending outward to Dangtu, letting the rivers and lakes within thousands of $l i$ surround one polder' as described in a poem by Yang Wanli (2011).

The polder fields were cultivated on the intertidal zones, and the silt-formed soil offered high fertility. As it was close to the river, easy irrigation together with the development of a large number of polder water conservancy projects made the land use rate and agricultural output of the region soar. According to the estimation (Guo 2009), the average agricultural output of polder fields in the south areas of the Yangtze River was 2 dan per $m u$ in the Song Dynasty, which supported 25\% of the population with $12 \%$ of the total farmlands in the country; in other words, each farmer could feed 2.35 families of five members. The significant increase in single family and total production had promoted the south area of the Yangtze River and Jiang-Huai regions as the most important grain producing areas and land of finance and tax from the Song Dynasty. As stated in the History of Song Dynasty: Biography of Fan Zuyu (Tuotuo 1985) 'the country is economically based on the southeast'.

At present, paddy field accounts for about $88 \%$ of the total farmland of Gaochun, where the main farmland is in the polder area. Since ancient times, Gaochun has been the granary of Lishui. According to the 2016 final accounts of the Department of Agriculture of Gaochun District published on the Nanjing government website, the district's grain output reached $456 \mathrm{~kg}$ per $m u$, which exceeded the average level per mu of the farmlands in the whole country by about 25 percent.

\section{Resilient Ecosystem and Agricultural Biodiversity}

The diversified species coexisting in Gaochun polder enjoyed a harmonious ecosystem with a variety of plants and crops in the longitudinal distribution. Vegetation could be seen in areas such as the field, the embankment, the slope and the water, which ensured the soil efficiency, maintenance of embankments and buffering of wind and waves. For example, growing rice and rearing fish and ducks at the same time in paddies created an excellent ecosystem that is beneficial for human-managed sustainable development; growing soybeans effectively saved land resources and improved soil fertility; woody or highstem herb crops such as willow and reed that were planted along the bank could not only grow luxuriantly but could also reinforce the embankment. It was recorded in History of the Song Dynasty (Tuotuo 1985) that planting trees like willow on the shore of the river would protect it from being destroyed by big wind or waves. Meanwhile, water plants such as Zizania aquatica, Nymphoides peltatum, and Euphorbia royleana could achieve the same result.

According to the Gaochun County Annals (Xue 1988), rice, wheat and rape were traditional agricultural products in Gaochun. Additionally, because of the large ditches in the polder field, the villagers also carried out the cultivation of fish, water chestnut and lotus, enriching the types of agricultural products. Moreover, local agricultural products include melon, hemp, wild mushroom, chestnut and others. A case in point is the plantation of rice among which various types and good quality were guaranteed. For example, Indica rice such as Huanglu Rice and glutinous rice such as sesame glutinous rice were all of good quality with large roots and big rice ears, but were also at high risk of lodging or falling down (Zhuang 2005). After the foundation of the People's Republic of China, more types of rice like early rice, late rice and medium Indica rice have been introduced to the market. However, the traditional paddy field is being ruined because of the promotion of crab breeding and expansion of ditches in the polder. Available space allows the plantation of multiple agricultural products such as melons, water chestnuts, lotus roots and fish breeding.

\section{Unique Farmland Water Conservancy System}

\section{River Dredging and Dike Construction}

The technology of water conservancy in Gaochun was well-developed in the Ming Dynasty and was one of the most important ways of alleviating flood damage. Specific methods such as river dredging and dike building were recorded in detail in Illustration and Methods of Polder Construction (Sun and Geng 1980), an expert of water conservancy in the Ming Dynasty.

Many technological achievements had been made such as the method of soil bulldozing, soil borrowing and balance of cut and fill. For instance, the excavation depth was calculated based on the water surface to ensure the flat bottom of the river bed during the process of river excavation. At the same time, the soil needed to be piled up in the right shape to prevent soil flowing into the river, which would delay the progress of the whole project. There were three main types of dikes. In the first situation, water was on both sides, so the dike needed to be fixed with wood piles and bamboo poles or repaired with stones; the other 
two types involved building dikes on the ground and the restoration of previous dikes, which were much easier to carry out than the first type. The method of moving and compacting earth is excerpted from Gaochun County Annals (Xue 1988). Generally, the earth taken from outside the embankment was used to build dikes; this also helps with dredging of new waterways. Moreover, different types of earth were treated in different ways. For example, workers who used the earth from Wu Mountain were asked to dig a 3-chi ( 1 chi equals approximately to 0.3 $\mathrm{m})$ ditch that was filled with muddy or white soil to form a solid clay wall; and they needed to compact the earth again every time the wall was thickened by $1.5 \mathrm{chi}$ to enhance its overall stability.

The original techniques and regulations have been adapted since then. New methods of renovation have been added to with the development of technology and relevant clauses that remind us to protect the dike are engraved on the stone tablets according to Gaochun County Annals (Xue 1988). For instance, dikes of the first type, the hardest one to build, were commonly consolidated with wood piles. Regulations like forbidding removing the earth, digging holes, shoveling grass and turning the soil within the embankment were also engraved on the stone tablets to inform passers-by to protect the dike.

\section{Classification of Irrigation Ditches}

The traditional grading system of irrigation canals and ditches could be traced back to the Changxing Collection and Wanchun Polder Records (Shen 1868) in the Song Dynasty. It was said that 'An area of 1 qing (3.33 ha) is divided into squares and surrounded by ditches. Every 4 qing of lands forms a block, and there are water channels, collecting the water from the ditches, round it.' There were three main canal levels, namely the outer channel, the main channel and the secondary channel. The first level of the water network was the basis of the overall pattern of the polder and the other two levels were responsible for transporting water to each field from the main stream. The water was harnessed in an environmentally-friendly way for polder reclamation and dike renovation (Liu and $\mathrm{Wu} 2014$ ).

The existing water network within the dike retains its original pattern and its features can be summarised by observation and measurement. The first-level water network, formed by river dredging or by building dikes, often accounts for a huge water volume. The second-level water network is at intervals of $600-700 \mathrm{~m}$, inside which relatively fixed units are conducive to farmers' cultivation and regional management. The third-level water network is mainly used for irrigation among which one or two fields is watered by a river at intervals of $100-200 \mathrm{~m}$. This hierarchically graded irrigation water network takes full advantage of local hydrological conditions, which assists agricultural farming through rational planning.

\section{Irrigation and Fallow System and Wheat-and-rice System}

Both the fallow system and the wheat-and-rice system (a farming method that aims to increase farmland yield) are important, and were commonly applied to traditional polder agriculture. Soil fertility can recover effectively through the method of irrigation and fallow because of the unique position of the polder. In the Song Dynasty, fields would be selected for two different usages. One was for farming and the other one was for recovering fertility by absorbing nutrients from the water. The maintenance of fertile land and reduction of artificial fertiliser were the two main advantages of this method (Wang 2008). This farming method depended on the re-precipitation of nutrients in the water to nourish the soil, which was different from the previous method where soil fertility was enhanced by planting soy beans. The other essential farming method was the wheat-and-rice system, where wheat/rape and rice were cultivated in turn according to their respective growth cycles. It was more commonly adopted by farmers in the Jiang-Huai area, while rice was often cultivated two or three times a year in the south of the Yangtze River.

Substantial gains have been made in the improvement of traditional technology in agriculture. As it is mentioned in the Gaochun Annals (Xue 1988), crops such as late rice have been introduced to further enhance land usability. Meanwhile, rape and japonica rice have been grown at larger scale than wheat and Indica rice because of their increased productivity.

\section{The Social Structure of the Polder Township}

The special geographical environment of polder fields means that the natural polders (wei) have become the basic condition of a water conservancy society, and that $w e i$ is the fundamental and administrative unit (Wang 2011). Such social structure was recorded in the Chongzhen Wu County Annals volume 9 (Fan 1990) as 'wei attached to $t u, t u$ administered by $d u$ ( $t u$ and $d u$ are two levels of rural administration)' 'connect $t u$ through wei, wei induces the fields', which formed the distinctive administrative establishment in regions south of the Yangtze River. The division of rural grass-roots organisations 


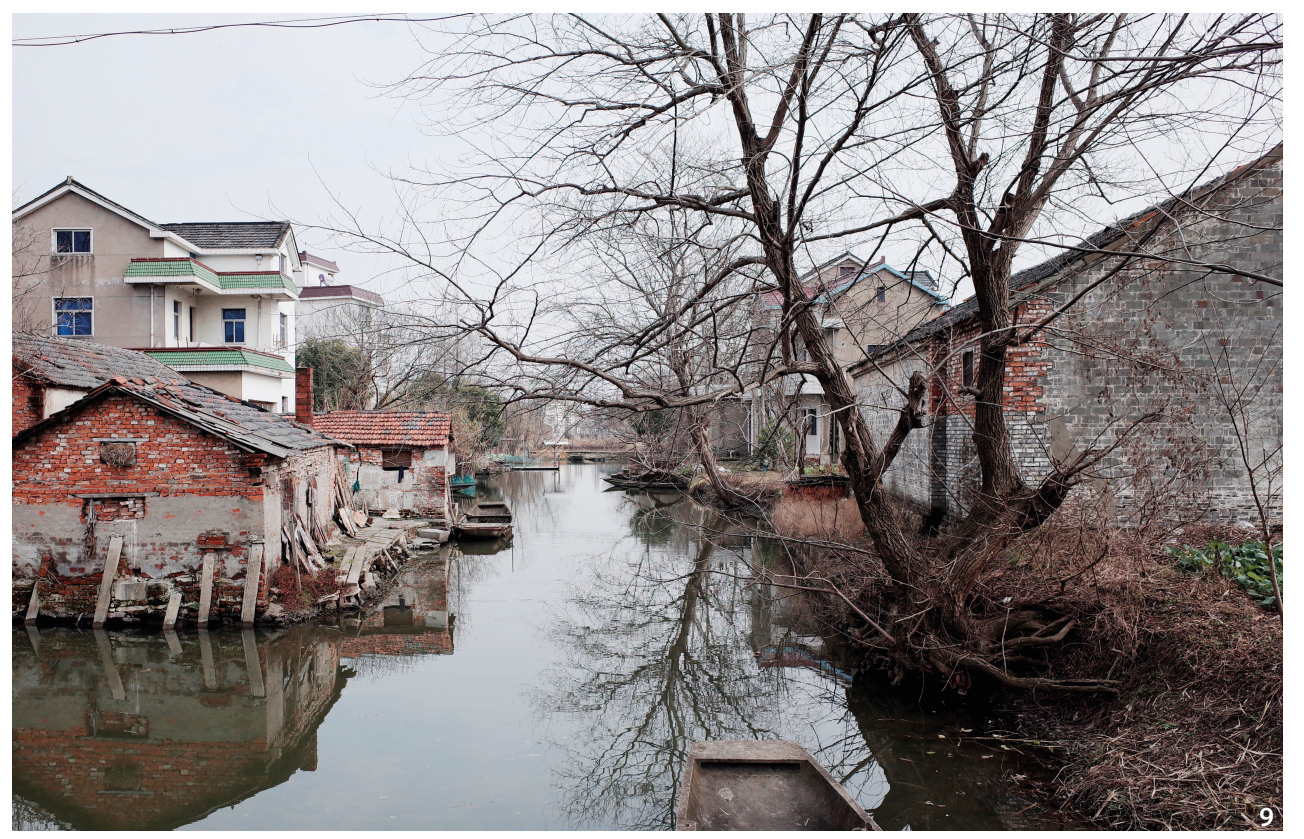

Figure 9 Photos of polder field village (Source: the author).

must be based on 'demarcate the boundary by dividing polders'. The pond master system, the river chief system (wei jia system), and the li jia organisation of state power, and all kinds of informal civil society groups took wei as the unit to carry out community relief and production management, which by default made the relief unit wei become the farmers' village in the polder area (Zhao and Liu 2003).

A variety of social organisations related to polder fields had also been one of the main links to maintain various relations among villages in the polder area. Through the observation of villages in the south of the Yangtze River, Xiaotong Fei (2005) found that the problems of water governance, booms, water competition and drainage within the village are basically based on a unit of natural polder (wei), so each wei is actually a community. However, in regions south of the Yangtze River in the Ming and Qing Dynasties (1368-1912), the grassroots administrative units, such as xiang $l i$ and $d u t u$, had changed their names to xiang wei or $d u$ wei in common usage. It had become a geographical community linked by the network of polder fields with local characteristics, as well as the social organisations established by the government, the gentry, villagers and other parties in accordance with the public interests of the polder areas.

Meanwhile, although each polder is relatively closed in space and isolated from the periphery, there is a symbiotic relationship among polders because of their similar and distinct natural environmental characteristics, and their reliance on the same large-scale water conservancy infrastructure. In the Ming Dynasty, various administrative intervention methods and spontaneous civil society groups successively contributed to the construction and management of the polder bank. On the basis of the lijia system, the administration sequence, 'the polder households-the polder chief-the pond master-the county official', of the township polder government was formed to coordinate the construction and management of polders. After the disintegration of the compulsory polder township system in the Qing Dynasty, xiangwei as an informal civil institution, still showed great social cohesion. Over time, a functional social organisation through interweaving and interaction came into being, with the villagers spontaneously employing waterwheels to bale, the polder chief leading the advocacy personally, the gentry sponsoring the supervision and the tenant farmers labouring for food supplied by the landlords (Wu 1995). At present, the polder is still the spatial basis of settlements in the polder area, and the natural villages are linearly gathered along the embankment, forming rural communities with close social interaction.

\section{The Rational Organisation of Field Patches and Rivers}

The agricultural landscape is an important part of the rural landscape. The relatively complex geographical environment and comprehensive agricultural development have jointly created the agricultural landscape system (Hou and Guo 2015). The agricultural landscape of Gaochun polder is composed of a hierarchical river network and ditch system, vast farmland within the polder, the 

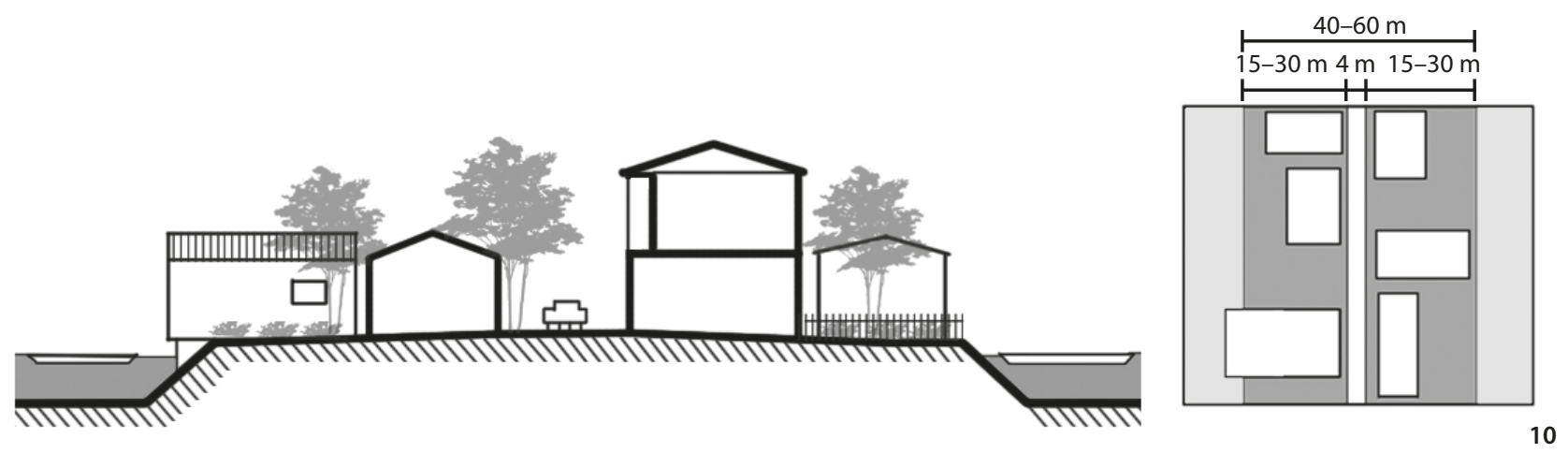

Figure 10 Diagrams of Jiageng village's architectural space (Source: the author).

embankment and the ridge. The area of each Gaochun polder is relatively large, the rivers are wide, and the overall landscape view is rather grand. The water network within the polder divides the patches of polder fields into unique patch landscapes (Figure 9).

At the same time, Gaochun has retained a relatively traditional farming lifestyle. Settlements in the polder area are often concentrated on the highlands of river ports and polder banks, which tend to be linear. The settlement was called 'safe highland' in the Illustration and Methods of Polder Construction (Sun and Geng 1980). The farmers enter farmlands through water barges and carry out daily activities at the water's edge, which interacts with the agricultural landscape. Meanwhile, the space of waterfront buildings has become an important part of the agricultural landscape of polder fields. For flood control considerations, most of the waterfront buildings are distributed along the embankment. In Jiageng Village (a typical residential area in Gaochun County), some buildings extend to the water and some of them shape a staggered shore line within the embankment, which brings a rich aesthetic experience in space (Figure 10).

\section{Conclusions and Suggestions}

In general, the Gaochun polder system possesses some prominent value of agricultural heritage, such as improving the efficiency of grain production to alleviate the contradiction between humans and land, maintaining a three-dimensional agricultural ecosystem with rich biological diversity, reflecting traditional water conservancy and farming technology with regional characteristics, breeding a special social organisation form of xiangwei (polder township), and forming a characteristic agricultural landscape where both natural and artificial traces coexist. The remaining contents and value of its different components are shown as follows (Table 1).
Because of the impact of new technology, marketisation and rapid urbanisation, the inheritance of many traditional agricultural systems is being threatened, and the original natural and social environment that has embodied these systems is also being impaired. These impacts result in the gradual disappearance of the characteristics and values of agricultural heritages, including Gaochun Polder.

Meanwhile, dynamic conservation should be taken into consideration. Traditional agriculture is geographically specific and evolves over time; this is why it tends to be sustainable. Koohafkan and Altieri (2011) introduced a methodological framework for the dynamic conservation of agricultural heritage systems. There are six steps: community involvement, identification of threats and challenges, identification of principles and best practices, action plans in market, ecotourism, policies, assessment of progress and final dissemination. In response to the problems faced by Gaochun Polder protection, the following measures can be taken.

First, local government should realise the importance of the protection of polder heritage, evaluate the status quo according to the construction time and the current integrity of the polders, and designate the scope of protection by regulation and legislation accordingly for landscape restoration and construction control. Second, a special institution should be established to clarify the rights and responsibilities of different stakeholders, coordinate the allocation of human and capital resources, and ensure the implementation of control and restoration measures. At the same time, public participation is also an important part of the protection, and the interests of farmers should be emphasised. As the most directly related interest groups in farmland, they have their own long-tested understanding on polders, which supplements the government's policy-making. Finally, to maintain the sustainability of this system, it is necessary to 
Table 1 The value composition of Gaochun Polder's agricultural heritage (Source: the author).

\begin{tabular}{|l|l|l|}
\hline \multicolumn{1}{|c|}{ Value Composition } & \multicolumn{1}{|c|}{ Carrier } & \multicolumn{1}{c|}{ Agricultural Heritage Value } \\
\hline $\begin{array}{l}\text { Farmland water } \\
\text { conservancy system }\end{array}$ & $\begin{array}{l}\text { Embankment, canals at different levels, } \\
\text { water culverts and steep gates }\end{array}$ & $\begin{array}{l}\text { It reflects the characteristics of water control in the low-lying areas of the } \\
\text { Yangtze River and the development of agricultural technology in farmland } \\
\text { irrigation. }\end{array}$ \\
\hline Farmland pattern & Traditional polders & It retains the original form of land use and its landscape feature. \\
\hline Farming technique & Rotation & It embodies the wisdom of long-term sustainable utilisation of land. \\
\hline Tool & Tools to build dykes and farm & It is an important part of water conservancy and agricultural technology. \\
\hline Social culture & (township polder) & It is a grass roots social organisation relying on special land forms. \\
\hline
\end{tabular}

establish a compensation mechanism for local ecological restrictions, as well as local cultural protection incentives. Two dimensions of traditional knowledge are relevant according to dynamic conservation frameworks: traditional management practices based on ecological knowledge and social mechanisms (rituals, folklore, ceremonies). By combining tourism development and ecological agricultural production, the traditional farmland will set up a new economic structure, expand the dimensions of industrial development, maintain its social and economic vitality as a community and set an example of a dynamic, multi-dimensional protection mechanism (Min 2006) for other agricultural heritage sites.

\section{References}

Altieri, Miguel A., and Parviz Koohafkan. 2004. "Globally Important Ingenious Agricultural Heritage Systems (GIAHS): Extent, Significance, and Implications for Development" In Proceedings of the Second International Workshop and Steering Committee Meeting for the Globally Important Agricultural Heritage Systems (GIAHS) Project. 7-9. Rome: The Food and Agriculture Organization (FAO) of the United Nations.

Fan, Chengda. 1999. Wujun zhi [Chronicles of Wu County]. Jiangsu: Jiangsu Ancient Classics Press.

Fan, Shen, ed. 1990. Volume 9 of Chongzhen Wuxian zhi [Chongzhen Wu County Annals]. Shanghai: Shanghai Bookstore Publishing House.

FAO (Food and Agriculture Organization). 2002. "Conservation and Adaptive Management of Globally Important Agricultural Heritage Systems (GIAHS). Global Environment Facility." Project Concept Note.

Fei, Xiaotong. 2005. Jiangcun Jingji: Zhongguo Nongmin de Shenghuo [Peasant Life in China: A Field Study of Country Life in the Yangtze Valley]. Bejing: The
Commercial Press.

Gaochun County Office. 2011. Gaochun nianjian [Gaochun County Yearbook] Bejing: Fangzhi Publishing House.

Guo, Kai. 2009. "Liangsong shiqi jiangnan weitian de fazhan jiqi yingxiang" [The Development and Influence of Jiangnan Putian in the Song Dynasty]. Master diss., Nanjing Agricultural University.

Guo, Wei, and Xiaolei Hou. 2015. "Shujun aishui he kaiken: Helan didi weitian jingguan fenxi” [Dredge, Drain and Reclaim Landscape Analysis of Polder Model in Dutch Lowlands]. Landscape Architecture 2015 (8): 16-22.

Guo, Wei, and Xiaolei Hou. 2016. "Zhutang, weiken yu dingju: Xiaoshao weiqu weitian jingguan fenxi" [Dyke, Reclamation and Settlement: Landscape Architectural Analysis of Polder Landscape in Xioashao Region] Chinese Landscape Architecture 2016 (7): 41-48.

He, Hongzhong. 2016. "Jishu lei nongye wenhua yichan de neihan yu baohu liyong" [Conservation of Technical Agricultural Heritage]. Agricultural Archaeology 2016 (04): 232-238.

He, Yongqiang. 2003. "Lun Tangsong shiqi weitian de sanzhong xingtai: yi Taihu liuyu de weitian wei zhongxin" [On Three Types of Morphology of Polders in Tang and Song Dynasty: Based on Polders in Taihu Lake Basin]. Zhejiang Academic Journal 2003 (2): 105-112.

Hou, Xiaolei, and Wei Guo. 2015. "Changsuo yu xiangchou- fengjing yuanlin shiye zhong de xiangtu jiangguan yanjiu fangfa tanjiu" [Research on Local Landscape Research Methods in Places and Homesickness]. Urban Studies 22 (4): 80-85.

International Institute for Land Reclamation and Improvement (ILRI). 1982. Keynotes International Symposium Polders of the World. Lelystad: ILRI.

Ji, Dunyu. 1964. "Hewei weitian? Qi fenbu diqu yu shengchan qingkuang zenyang?” [What Is Polder? How Is It Distributed and How Does It Procuce?]. History 
Teaching 1964 (8): 54-55.

Koohafkan, Parviz, and Miguel Altieri. 2011. A Methodological Framework for The Dynamic Conservation of Agricultural Heritage Systems. Geneva, SUI: Land and Water Division. The Food and Agriculture Organization (FAO) of the United Nations.

Kuo Shen. 1868. Wanchun wei tuji [Wanchun Polder Records] Volume 21 of Changxing ji [Changxing Collection]. Beijing: Siku Publishing House.

Liu, Tong, and Danzi Wu. 2014. "Fengjing yuanlin xue shijiao xia de xiangtu jingguan yanjiu: yi Taihu liuyu shuiwang pingyuan weili" [Research on Local Landscape from the Perspective of Landscape ArchitectureTaking the Water Network Plain in Taihu Basin as an Example] Chinese Landscape Architecture 2014 (12): 40-43.

Lu, Yingcheng, Xinyuan Wang, Huafeng Zhuang and Chao Gao. 2006. "Jiyu yaogan xinxi de huandongnan weitian tuxing jiegou tezheng" [Structural Features and Functions Analyse of Polder Fields in Southeastern Anhui Province Based on Remote Sensing Information] Journal of Anhui Normal University (Natural Science) 2006 (1): 75-78.

Meeus, J. H. A. 1995. "Pan-European landscapes" Landscape and Urban Planning 31 (1-3): 57-79.

Min, Qingwen, Lu He, and Dan Zhang. 2011. "Agricultural heritage research in China: Progresses and perspectives." Journal of Resources and Ecology 2011 (2.1): 15-21.

Min, Qingwen. 2006. “Quanqiu zhongyao nongye wenhua yichan" [Global Important Agricultural Cultural Heritage-A New Type of World Heritage]. Journal of Resources Science 2006 (4): 206-208.

Nijhuis, Steffen. 2016. "Polderscapes: The Landscape Architecture of the Dutch Lowlands." Landscape Architecture 2016 (8): 38-57.

Ning, Ke. 1958. "Songdai de weitian" [Polders of Song Dynasty]. Journal of Historical Science 1958 (12): 21-25.

Segeren, W. A. 1983. "Introduction to Polders of the World" Water International 8 (2): 51-54.

Sun, Jun, and Ju Geng. 1980. Zhuwei tushuo ji zhuwei fa [Illustration and Methods of Polder Construction]. Beijing: Agriculture Press.

Tuotuo. 1985. Volume 24 of Songshi [The history of Song Dynasty]. Beijing: Zhonghua Publishing House.

UNESCO. 1999. "World Heritage List: Droogmakerij de Beemster (Beemster Polder).” Accessed 25 Dec 2018. https://whc.unesco.org/en/list/899

Wang, Cun. 1984. Yuanfeng Jiuyu zhi [China Annals of
Yuanfeng]. Beijing: Zhonghua Publishing House.

Wang, Jiange. 2008. "Songyuan shiqi Wusongjiang weitian qu de gengzuozhi yu nongtian jingguan" [Farming System and Farmland Landscape in Wusongjiang During the Song and Yuan Dynasties]. Ancient and Modern Agriculture 2008 (4): 30-41.

Wang, Jiange. 2011. "Mingdai jiangnan de shuili danwei yu defang zhidu yi changshu weili" [Water Conservancy Units and Regulations in Jiangnan in the Ming Dynasty: Taking Changshu as an Example]. Chinese History Research 2011 (2): 165-179.

Wang, Siming, and Yong Lu. 2010."Zhongguo de nongye yichan yanjiu: jinzhan yu bianhua" [China's Agricultural Heritage Research: Progress and Change]. Agricultural History of China 2010 (1): 3-11.

Wang, Zhen. 2015. Volume 7 of Nongshu [Book on Argriculture]. Hangzhou: Zhejiang People's Fine Arts Publishing House.

Wu, Tao. 1995. "Mingqing JiangnaN diqu de xiangwei" [The Polders in the Jiangnan Area in the Ming and Qing Dynasties]. Agricultural History of China 1995 (3): $54-61$.

Xue, Xingxiang. 1988. Gaochun xian zhi [Gaochun County Annals]. Nanjing: Jiangsu Guji Publishing House.

Yang, Wanli. 2011. Weiding ci shi jie $x u$ [The Introductory of Ten Interpretations of Song Lyric Verses on Polder Farmers] Vol. 325 of Chengzhai Ji [Chengzhai Collection]. Taipei: The Commercial Press.

Zhao, Cuili, and Xinwei Liu. 2003. "Jin bange shiji yilai Zhongguo gudai weitian yanjiu zongshu" [A Review of Ancient Chinese Polder Research in the Past Half Century]. Ancient and Modern Agriculture 2003 (3): 58-69.

Zhuang, Huafeng. 2005. "Gudai Jiangnan diqu weitian kaifa jiqi dui shengtai huanjing de yingxiang" [Development of Weitian in Ancient Jiangnan Area and Its Impact on Ecological Environment]. Chinese Historical and Theoretical Theory 2005 (03): 87-94. 